\title{
The Synthesis of Rigid Polycyclic Structures for the Study of Diatropic or Steric Effects of a Phenyl Ring on CF Bond
}

\author{
Yung-Yu Chang, I-Ting Ho, Tse-Lok Ho,* and Wen-Sheng Chung* \\ Department of Applied Chemistry, National Chiao-Tung University, Hsinchu 30050, Taiwan ROC \\ Supporting Information
}

ABSTRACT: Polycyclic compounds $1 \mathrm{a}-\mathrm{c}$ were synthesized to study the diatropic effects of a flanking phenyl ring on nearby $\mathrm{CH}$ and CF bonds. ${ }^{19} \mathrm{~F}$ NMR spectra of $\mathbf{1 b}$ and $\mathbf{1 c}$ were strongly deshielded compared with those of the ring-opened compounds $3 \mathbf{b}$, $7 \mathbf{b}$, and 7 c. DMol3 calculations on $1 \mathbf{a}-\mathbf{c}$ provided quantitative bond lengths and torsional angles to support the conclusion that the downfield shifts in the ${ }^{19} \mathrm{~F}$ NMR spectra are mainly due to steric interactions between the CF bonds and the $\pi$ clouds of the phenyl $\operatorname{ring}(\mathrm{s})$.

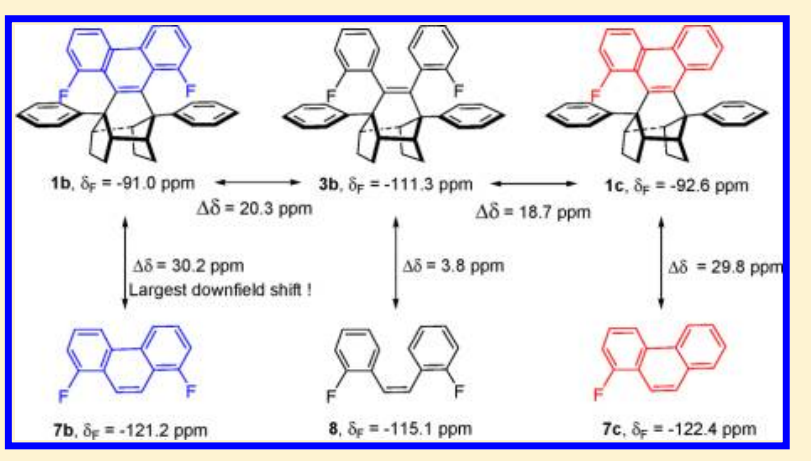

Tnter- and intramolecular $\mathrm{CH}-\pi$ and $\mathrm{CF}-\pi$ interactions play important roles in host-guest chemistry, molecular assembly, and the folding of proteins and polynucleotides. ${ }^{1}$ The $\mathrm{CH}-\pi$ interaction is a weak force $(0.5-2.5 \mathrm{kcal} / \mathrm{mol})^{2 \mathrm{a}}$ that is usually difficult to measure directly using molecules with flexible conformations. Therefore, the measurement of this weak interaction in molecules with intramolecular folding and unfolding has intrigued chemists for decades. ${ }^{2}$ Recently, Tsuzuki $^{3 \mathrm{a}}$ reported an excellent review that summarizes recently reported gas-phase measurements and high-level ab initio calculations of the $\mathrm{CH}-\pi$ interactions. $\mathrm{Ab}$ initio calculations show that the major source of attraction in the $\mathrm{CH}-\pi$ interactions is the dispersion interaction, while the contribution from electrostatic interactions is small. On the other hand, Nishio et al. ${ }^{\text {b }}$ surveyed and analyzed literature results relevant to the $\mathrm{CH}-\pi$ interactions in crystal packing and conformations based on data reported in crystallographic databases (CSD and PDB). Moreover, as the organofluoride compounds are getting more popular in medicinal chemistry, the need to study $\mathrm{CF}-\pi$ interactions in organic and biological molecules has markedly increased. In order to study such $\mathrm{CF}-\pi$ interactions efficiently, one needs to have a special molecular design in which the CF bond is pointing toward conformationally rigid $\pi$ bonds or aromatic rings. ${ }^{4}$

In previous literature, the typical $\mathrm{CF}-\pi$ interactions between fluoromethane and benzene/hexafluorobenzene were only theoretically studied. For example, the very weak attractive interaction between the fluorine of HF and hexafluorobenzene was measured on the basis of theoretical calculations. ${ }^{5 a}$ Kawahara also indicated that a weak interaction between fluoromethane and hexafluorobenzene was observed; furthermore, it is worth noting that this was an attractive force. ${ }^{5 b}$ Nowak, however, studied $\mathrm{CF}-\pi$ interactions by measuring the effect of fluorine on the reactivity of a proximal double bond using a polyfluorinated indacene system. ${ }^{6}$ The through-space interactions between the CF bond and the $\pi$ electrons of alkenes were explained by Lectka ${ }^{7}$ to be due to steric hindrance, anchimeric assistance, and the repulsive interactions from overlap of lone-pair electrons on fluorine with the $\pi$ electrons on the olefin. Furthermore, they reported that the fluorine was little perturbed by anisotropic effects from the $\pi$ electrons of the alkene, and only a slight upfield shift relative to theoretical values of fluorine chemical shifts was observed. ${ }^{7}$ We report here the synthesis of the rigid polycyclic compounds $\mathbf{1 a}-\mathbf{c}$ and subsequent NMR spectral studies and theoretical calculations to measure the diatropic effect of a phenyl ring on sterically close aryl $\mathrm{CH}$ (1a) and CF bonds (1b and $\mathbf{1 c})$.

Tandem Diels-Alder reactions followed by sequential photocyclization reactions were the two key steps in our synthesis of the rigid polycyclic structures $1 \mathbf{a}-\mathbf{c}$. One of us ${ }^{8 \mathrm{a}}$ and Winkler ${ }^{8 \mathrm{~b}}$ have provided excellent reviews of tandem Diels-Alder reactions demonstrating that they are exceptionally powerful methods in the synthesis of intricate polycarbocycles. ${ }^{8,9}$ Iodine-induced photocyclization of stilbene to phenanthrene has also been well-studied. ${ }^{10}$ The $\mathrm{CH}$ and $\mathrm{CF}$ bonds in the series of polycyclic frameworks $\mathbf{1 a}-\mathbf{c}$ can be arranged in a very close proximity to the aromatic ring, and hence, ${ }^{1} \mathrm{H}$ and/or ${ }^{19} \mathrm{~F}$ NMR spectroscopy can be used to estimate the strength of the interactions between them and the $\pi$-cloud of the phenyl ring. Moreover, theoretical calculations were carried out on the polycyclic frameworks $1 \mathbf{a}-\mathbf{c}$ to obtain optimized geometries, bond distances, and torsional angles.

Synthesis of 1a. Compound 1a was obtained through a twostep sequence that started by refluxing tetraphenylcyclopentadienone (2a) with 1,5-cyclooctadiene to afford compound $3 \mathrm{a}^{9}$ in $71 \%$ yield (Scheme 1 ). Iodine-catalyzed photocyclization ${ }^{10}$

Received: October 4, 2013

Published: December 10, 2013 
Scheme 1. Synthesis ${ }^{a}$ and X-ray Crystal Structure of 1a

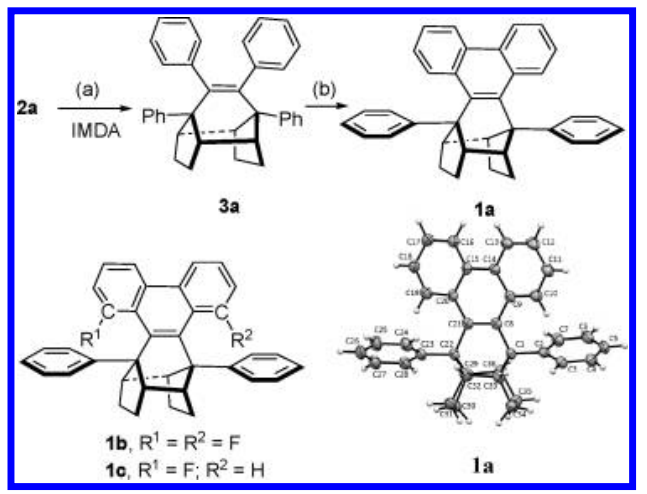

${ }^{a}$ Reagents and conditions: (a) 1,5-cyclooctadiene, reflux, 4 days, $71 \%$; (b) $\mathrm{I}_{2}$, toluene, Rayonet, $300 \mathrm{~nm}, 58 \%$.

of $\mathbf{3 a}$ in toluene afforded the target polycyclic compound $\mathbf{1 a}$ in $58 \%$ yield. Because the target compounds $1 \mathrm{a}$ and $3 \mathrm{a}$ have similar polarities $\left(R_{\mathrm{f}}=0.5\right.$ in hexane eluent), it was difficult for us to obtain pure 1a even after repeated column chromatography. The ${ }^{1} \mathrm{H}$ NMR spectrum of the purified sample of 1a still showed about $10 \%$ of the starting material 3a; however, their signals can be easily discerned through chemical shift analysis. In particular, a new doublet signal around 8.5 ppm appeared, which is regarded as one of the characteristic protons of the phenanthrene ring in 1a. Moreover, the signals of the aromatic protons of 1a showed a significant downfield shift compared with those of 3a (Figure S18 in the Supporting Information). Furthermore, the formation of 1 a could be easily recognized by GC-MS analysis, which showed a new peak with retention time $\left(r_{\mathrm{t}}\right)$ of $50.9 \mathrm{~min}$ (with $\mathrm{m} / z$ 462.5) as opposed to the peak for the starting material 3a at $r_{\mathrm{t}}=33.6 \mathrm{~min}$ (with $\mathrm{m} / \mathrm{z} 464.6$ ) (see Figure S20 in the SI). Finally, we were lucky to obtain a single crystal of 1a by crystallization from a mixed solvent of dichloromethane and ethanol $(2: 8 \mathrm{v} / \mathrm{v})$. The single-crystal Xray structure of $\mathbf{1 a}$ (shown in Scheme 1) proved that it has a rigid polycyclic structure.

Synthesis of $\mathbf{1 b}$. Encouraged by the successful synthesis of the polycyclic compound 1a, we then applied this methodology to construct the fluoride analogue $\mathbf{1 b}$. The synthesis of fluorinated substrates $\mathbf{2 b}$ and $\mathbf{3 b}$ is shown in Scheme 2. The fluorinated substrate $\mathbf{2 b}$ was obtained through a three-step synthesis. First, the benzoin condensation of 2-fluorobenzene was conducted using catalytic amount of sodium cyanide in ethanol to give the desired product, $2,2^{\prime}$-difluorobenzoin (5), ${ }^{11}$ in $72 \%$ yield. Benzoin 5 was then oxidized by copper(II) acetate in $80 \%$

Scheme 2. Synthesis of $2 b$ and $3 b^{a}$

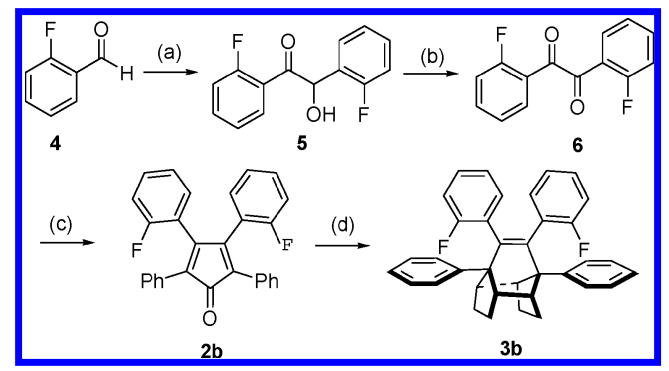

${ }^{a}$ Reagents and conditions: (a) cat. $\mathrm{NaCN}, \mathrm{EtOH}$, reflux, $3 \mathrm{~h}, 72 \%$; (b) $\mathrm{Cu}(\mathrm{OAc})_{2}, 80 \% \mathrm{AcOH}$, reflux, $2 \mathrm{~h}, 72 \%$; (c) $\mathrm{KOH}$, dibenzyl ketone, EtOH, reflux, 1 h, 35\%; (d) 1,5-cyclooctadiene, reflux, 24 h, $68 \%$. acetic acid to afford $2,2^{\prime}$-difluorobenzil $(6)^{11}$ in $72 \%$ yield. Subsequent aldol condensation of 6 with dibenzyl ketone under alkaline conditions gave the difluorinated substrate $\mathbf{2 b}$ in $35 \%$ yield. After tandem Diels-Alder reactions of $\mathbf{2 b}$ with 1,5cyclooctadiene, we obtained precursor $3 \mathrm{~b}$ in $68 \%$ yield. The photocyclization of $\mathbf{3 b}$ with a catalytic amount of iodine was conducted by irradiation in a Rayonet photoreactor $\left(\lambda_{\max }=250\right.$ $\mathrm{nm}$ ) at room temperature (Scheme 3 ). The photocyclization

\section{Scheme 3. Products of the Photocyclization of $3 b$}

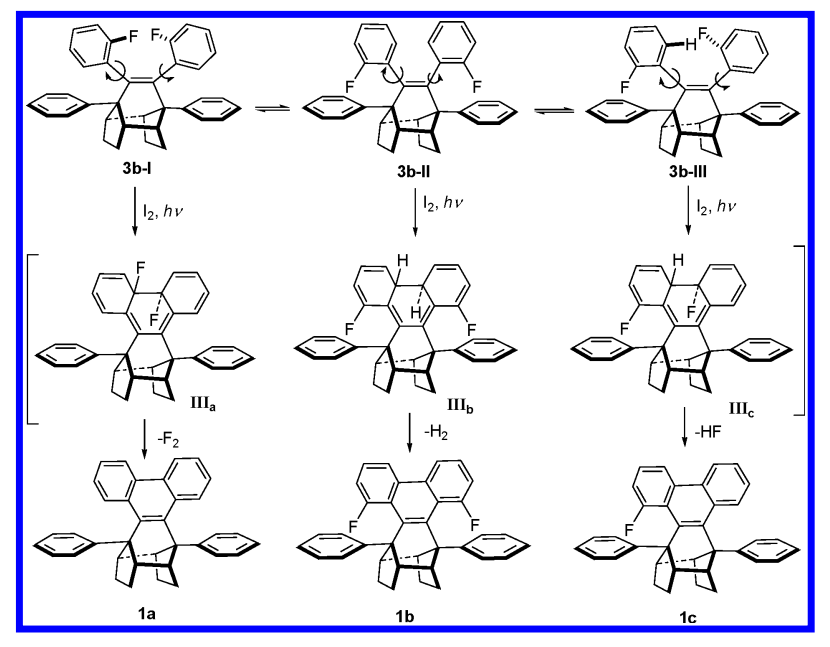

reaction of $\mathbf{3 b}$ was monitored by ${ }^{1} \mathrm{H}$ NMR spectroscopy (Figure S17 in the Supporting Information). After irradiation at $250 \mathrm{~nm}$ for $10 \mathrm{~min}$, new signals around $\delta_{\mathrm{H}}=8-9 \mathrm{ppm}$ emerged, while signals of the aromatic protons of the starting compound $\mathbf{3 b}$ gradually decreased. The photocyclization reaction of compound $3 \mathbf{b}$ was completed within $6 \mathrm{~h}$ of irradiation at $254 \mathrm{~nm}$.

Similar to the trouble we met in purifying the products of the photocyclization of $3 a$, we also had difficulty in purifying the products of the photocyclization of $3 \mathbf{b}$ because products $1 \mathbf{a}-\mathbf{c}$ have similar polarities. Even after separation by column chromatography and recrystallization, the reaction mixture analyzed by HPLC still showed three major peaks at $r_{\mathrm{t}}=23.9$, 24.8 , and $25.9 \mathrm{~min}$ with an area ratio of 8:85:5 (Figure S21 in the Supporting Information). The three products were recognized by mass spectrometry as $\mathbf{1} \mathbf{b}\left(r_{\mathrm{t}}=23.9 \mathrm{~min}, \mathrm{~m} / z\right.$ 498), 1c $\left(r_{\mathrm{t}}=24.8 \mathrm{~min}, \mathrm{~m} / z 481\right)$, and 1a $\left(r_{\mathrm{t}}=25.9 \mathrm{~min}, \mathrm{~m} / z\right.$ 463) (see Scheme 3). Notably, photolysis of $3 \mathbf{b}$ afforded not only the prospective fluorine product $\mathbf{1 b}$ but also the defluorinated and dehydrofluorinated side products 1a and 1c (Figures S20 and S21 in the Supporting Information). The structure of 1a was fully characterized by ${ }^{1} \mathrm{H}$ and ${ }^{13} \mathrm{C}$ NMR, DEPT-135, HRMS, and single-crystal X-ray analysis (vide supra and the Experimental Section). Photolysis of compound $\mathbf{3 b}$ in the presence of a catalytic amount of iodine may extrude $\mathrm{F}_{2}(\mathrm{~g})$, $\mathrm{H}_{2}(\mathrm{~g})$, and $\mathrm{HF}(\mathrm{g})$ from the difluorodihydrophenanthrene intermediates IIIa-c, leading to the formation of the aromatized products ${ }^{10 a} \mathbf{1 b}, \mathbf{1 c}$, and $\mathbf{1 a}$ in $8 \%, 85 \%$, and $5 \%$ yield, respectively, based on HPLC area ratios (Scheme 3 ).

Three factors must have played important roles in the conformational distributions of $\mathbf{3} \mathbf{b}$ in its ground state (Scheme 3): (1) intramolecular electronic repulsion between the two CF bonds in 3b-I, (2) intramolecular steric hindrance between the two CF bonds and the flanking phenyl rings in 3b-II, and (3) intramolecular hydrogen-bonding interactions between $\mathrm{CF}$ and 
$\mathrm{CH}$ bonds in $\mathbf{3 b}$-III. Among the three major conformations of $3 \mathbf{b}$, the conformer $3 \mathbf{b}$-III became the most stable one and therefore led to the formation of compound $1 \mathrm{c}$ as the major product ( $85 \%$ in HPLC ratio).

All attempts to separate the product mixtures failed, and we could only collect a small amount of $1 c$ by analytical HPLC separation. After obtaining the fluorinated polycyclic compound $\mathbf{1 c}$ and the mixture of $\mathbf{1 b}$ and $\mathbf{1 c}$, we then took the intended measurement on $\mathrm{CF}-\pi$ interaction using ${ }^{19} \mathrm{~F}$ NMR spectroscopy. The ${ }^{19} \mathrm{~F}$ NMR spectra of $\mathbf{1 b}, \mathbf{1 c}$, and $\mathbf{3 b}$ showed the fluorine peaks at $-91.0,-92.6$, and $-111.3 \mathrm{ppm}$, respectively, using hexafluorobenzene $\left(\delta_{\mathrm{F}}=-162.2 \mathrm{ppm}\right)^{12}$ as an external standard. To our big surprise, the ${ }^{19} \mathrm{~F}$ NMR peaks of $\mathbf{1 b}$ and $1 \mathrm{c}$ were downfield-shifted by 20.3 and $18.7 \mathrm{ppm}$, respectively, compared with that of $3 \mathbf{b}$ (Figure $\mathrm{S} 15$ in the Supporting Information); however, they were downfield-shifted by 30.2 and $29.8 \mathrm{ppm}$ compared with those of 1,8 difluorophenanthrene $7 \mathbf{b}\left(\delta_{\mathrm{F}}=-121.2 \mathrm{ppm}\right)^{13 \mathrm{c}}$ and 1fluorophenanthrene $7 \mathrm{c}\left(\delta_{\mathrm{F}}=-122.4 \mathrm{ppm}\right){ }^{13 \mathrm{a}}$ respectively. Furthermore, compound $\mathbf{3 b}$ is downfield-shifted by $3.8 \mathrm{ppm}$ compared with $8\left(\delta_{\mathrm{F}}=-115.1 \mathrm{ppm}\right) .{ }^{13 \mathrm{~b}}$ Since the $\mathrm{C}-\mathrm{F}$ bonds of $\mathbf{1 b}$ and $\mathbf{1 c}$ are located very close to their phenyl rings, one would have expected to see a significant upfield shift in their ${ }^{19} \mathrm{~F}$ NMR resonances due to the diatropic shielding effect of the phenyl rings. To our surprise, the fluorine chemical shifts of $\mathbf{1 b}$ and $1 \mathrm{c}$ did not show any shielding effect of the phenyl ring but instead showed strong deshielding (vide supra)!! Thus, the diatropic shielding effect of phenyl rings did not seem to play any role in determining the fluorine chemical shift of the $\mathrm{C}-\mathrm{F}$ bond, and other factors must have played more important roles leading to the significant downfield shift of the ${ }^{19} \mathrm{~F}$ NMR peaks of $\mathbf{1 b}$ and $\mathbf{1 c}$.

It has been reported that the ring-current effect is relatively less important in ${ }^{19} \mathrm{~F}$ NMR than in ${ }^{1} \mathrm{H}$ NMR, ${ }^{14 a, b}$ whereas steric effects have a stronger influence on the chemical shift in ${ }^{19} \mathrm{~F}$ NMR. Even though the strong deshielding of the ${ }^{19} \mathrm{~F}$ NMR peaks of $\mathbf{1 b}$ and $\mathbf{1 c}$ were opposite to what we originally expected, the results are fully explainable by steric effects in fluorine NMR. ${ }^{14 a, b}$ The fluorine chemical shifts of para- and meta-substituted fluorobenzenes showed a reasonable correlation with the resonance and inductive effects of the substituents; ${ }^{14 \mathrm{i}-\mathrm{k}}$ however, because of the intramolecular steric effect between these substituents and the adjacent fluorine atom, the fluorine chemical shifts of ortho-substituted fluorobenzenes exhibit a poor correlation. ${ }^{14 i-k}$ Dolbier and others ${ }^{13,14}$ reported that all sterically congested or hindered organofluoride compounds are downfield-shifted in ${ }^{19} \mathrm{~F}$ NMR compared with those that are sterically unhindered (see Table 1). For example, the ${ }^{19} \mathrm{~F}$ NMR peaks of cis-9-11 were downfield-shifted by 3-6 ppm compared to those of trans-9$11 ;^{14 a-c}$ furthermore, the peaks of cis-13-15 were downfieldshifted by $1-8 \mathrm{ppm}$ compared with those of trans $-13-15$. $^{14 \mathrm{~d}-\mathrm{f}}$ The deshielding effect of a bulkier substituent on the ${ }^{19} \mathrm{~F}$ NMR spectrum is even more obvious in compounds $12 \mathbf{a}-\mathbf{d}$, where the ${ }^{19} \mathrm{~F}$ NMR peak of $\mathbf{1 2 d}$ shows the largest downfield-shift effect when its 8 -substituent changed from $\mathrm{H}$ to $t$ - $\mathrm{Bu}(\Delta \delta=$ $27.5 \mathrm{ppm}) .^{14 \mathrm{a}, \mathrm{b}}$

In addition, Lectka and co-workers ${ }^{7}$ synthesized compounds $16 \mathrm{a}$ and $16 \mathrm{~b}$ to investigate the intramolecular $\mathrm{CF}-\pi$ interactions. The $\mathrm{C}-\mathrm{F}$ bond of $\mathbf{1 6 b}$ is very close to a double bond, causing a $16.0 \mathrm{ppm}$ downfield shift of its ${ }^{19} \mathrm{~F}$ NMR resonance compared with that of $16 a^{7}$ The ${ }^{19} \mathrm{~F}$ NMR peak of 4-fluoro[2.2] paracyclophane $(17),{ }^{14 \mathrm{~g}}$ which has its CF bond
Table 1. ${ }^{19}$ F NMR Data for Organofluoride Compounds $1 \mathbf{b}$, $1 c, 3 b$, and $7-18^{13,14}$

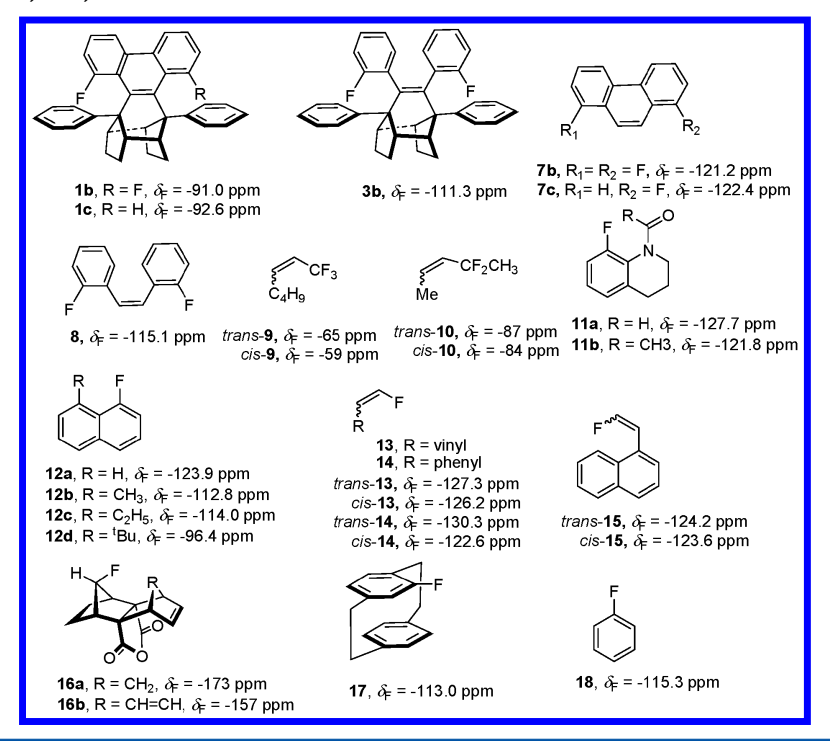

parallel to a nearby phenylcyclophane, was downfield-shifted by only $2.3 \mathrm{ppm}$ compared with that of fluorobenzene $(\mathbf{1 8}) \cdot{ }^{14 \mathrm{~h}} \mathrm{It}$ is important to note that our molecules $\mathbf{1 b}$ and $\mathbf{1 c}$ exhibited downfield shifts of 30.2 and $29.8 \mathrm{ppm}$ in their ${ }^{19} \mathrm{~F}$ NMR spectra compared with those of $7 \mathbf{b}$ and $7 \mathbf{c}$, respectively, which are by far the largest downfield shift effects ever reported. Thus, a nearby $\pi$ cloud mainly exerts a steric effect on the ${ }^{19} \mathrm{~F}$ NMR peak of a CF bond instead of the traditional diatropic effect and therefore leads to strong downfield shifts of molecules $\mathbf{1 b}$ and $1 c$.

The fluorine chemical shifts of compounds $\mathbf{1 b}$ and $\mathbf{1 c}$ were also calculated by means of a published method, ${ }^{17}$ namely, gauge including atomic orbitals (GIAO) combined with B3LYP DFT using the cc-pVTZ basis set. The calculated fluorine chemical shifts of compounds $\mathbf{1 b}\left(\delta_{\mathrm{F}}=-101.9 \mathrm{ppm}\right)$ and $\mathbf{1 c}$ $\left(\delta_{\mathrm{F}}=-101.0 \mathrm{ppm}\right)$ are upfield-shifted by 10.9 and $8.4 \mathrm{ppm}$ compared with the observed values (Table S10 in the Supporting Information).

DMol3 Calculations of the Conformations of $\mathbf{1 a - c}$. In order to rationalize the conformations of $1 \mathbf{a}-\mathbf{c}$, we also calculated their geometry-optimized structures by the DMol3 molecular modeling method ${ }^{15 \mathrm{a}, \mathrm{b}}$ and simulated in a $\mathrm{CHCl}_{3}$ environment, in which the B3LYP functional with the double-numeric-quality with polarization functions (DNP) basis set was used. The size of the DNP basis set is comparable to that of the Gaussian 6$31 \mathrm{G}^{* *}$ basis set, but DNP is more accurate than a Gaussian basis set of the same size. ${ }^{15 c}$ The optimized geometries of $1 \mathrm{a}-\mathrm{c}$ are displayed and related data of these calculations are summarized in Tables S1-S6 in the Supporting Information). In the optimized geometries of $\mathbf{1 a}-\mathbf{c}$, the distances between the tips of the $\mathrm{C}-\mathrm{H}$ and $\mathrm{C}-\mathrm{F}$ bonds to the center of a phenyl ring were measured to be $2.737,3.367$, and $3.393 \AA$, respectively. For most literature reports on $\mathrm{CH}-\pi$ interactions, the distances between the tip of the $\mathrm{C}-\mathrm{H} / \mathrm{C}-\mathrm{F}$ bond to the center of a phenyl ring range from 2.9 to $3.5 \AA$ (typically $3.05 \AA$ ). ${ }^{2 c, 3 b, 16}$ Even though the $\mathrm{C}-\mathrm{H}$ bonds of phenanthrene on 1a are not pointing toward its flanking phenyl rings, they still fit conventional $\mathrm{CH}-\pi$ interaction characteristics. The $\mathrm{C} 10-$ C9-C8-C1 torsional angles, $\Phi$, of $1 \mathbf{a}-\mathbf{c}$ were calculated to be $20.5^{\circ}, 28.8^{\circ}$, and $35.0^{\circ}$, respectively, suggesting the increase in repulsive interaction between $\mathrm{CH} / \mathrm{CF}$ bonds and a phenyl ring, 
as one would expect from the overlap of the $\pi$ system with the fluorine or hydrogen atoms. As a result of the steric hindrance between phenanthrene and the flanking phenyl rings in the crystal structure of 1a, the conformations of phenanthrene and the cyclic skeleton $(\mathrm{C} 1-\mathrm{C} 33-\mathrm{C} 32-\mathrm{C} 22-\mathrm{C} 29-\mathrm{C} 36)$ in 1a are nonplanar and a twisted boat, respectively. The distance between the tip of the $\mathrm{CH}$ bond and the center of a phenyl ring was determined to be $2.567 \AA$, and the torsional angle $\Phi$ of 1a was shown to be $18.0^{\circ}$, so the Dmol3-calculated results for 1a were very close to those of the crystal structure of 1a. We infer that steric hindrance plays a pivotal role in the interactions between the CF bond(s) and the phenyl ring(s) in $\mathbf{1 b}$ and $\mathbf{1 c}$, leading to their strong deshielding in the ${ }^{19} \mathrm{~F}$ NMR spectra compared with those without such a sterically hindered environment.

In conclusion, we have designed and synthesized a series of rigid polycyclic structures $1 \mathrm{a}-\mathrm{c}$ where the key steps of the synthesis involves (1) tandem Diels-Alder reactions and (2) the photocyclization followed by extrusion of $\mathrm{F}_{2}, \mathrm{H}_{2}$, and $\mathrm{HF}$ from the difluorodihydro- phenanthrene intermediates IIIa-c, respectively. According to the observed ${ }^{19} \mathrm{~F}$ NMR of $\mathbf{1 b}$ and $\mathbf{1 c}$, their chemical shift were downfield shifted by 30.2 and 29.8 ppm when compared to those of the $7 \mathbf{b}$ and $7 \mathbf{c}$, respectively. Even though the strong deshielding of the ${ }^{19} \mathrm{~F}$ NMR of $1 \mathrm{c}$ was opposite to what we originally expected, the results are fully explainable by "steric effect" on fluorine NMR. The torsional angles of $1 \mathrm{a}-\mathrm{c}$ increased from $20.5^{\circ}$ in $\mathbf{1 a}$, to $28.8^{\circ}$ in $\mathbf{1 b}$, and $35.0^{\circ}$ in $1 \mathrm{c}$, suggesting the increase in repulsive interaction between $\mathrm{C}-\mathrm{H} / \mathrm{C}-\mathrm{F}$ bonds and a phenyl ring. We conclude that steric hindrance must have played a pivotal role in the interaction between the CF bond and the phenyl ring in 1c, leading to its strong deshield in ${ }^{19} \mathrm{~F}$ NMR compared to those without such a steric hindered environment.

\section{EXPERIMENTAL SECTION}

General Methods. Column chromatography was performed on $70-230$ or $230-400$ mesh silica gel; thin-layer chromatography (TLC) was performed on aluminum plates coated with silica gel 60 $\mathrm{F}_{254}$. Melting points were determined with a melting-point apparatus and are uncorrected. ${ }^{1} \mathrm{H}$ NMR spectra were measured with a $300 \mathrm{MHz}$ spectrometer with the residual solvent peak (usually $\mathrm{CHCl}_{3}$ or DMSO- $\left.d_{6}\right)$ as the internal standard. Natural-abundance ${ }^{13} \mathrm{C}$ NMR spectra were recorded using pulse Fourier transform techniques with a $300 \mathrm{MHz}$ spectrometer operating at $75.4 \mathrm{MHz} .{ }^{19} \mathrm{~F}$ NMR spectra were measured on a $470 \mathrm{MHz}$ spectrometer with the solvent peak $\left(\mathrm{C}_{6} \mathrm{~F}_{6}\right)$ as an external standard $\left(\delta_{\mathrm{F}}=-162.2 \mathrm{ppm}\right){ }^{12}$ High-resolution mass spectrometry (HRMS) was performed with a magnetic-sector-type analyzer using the EI method. UV/vis spectra were recorded with a spectrophotometer, and solvents were of HPLC grade. HPLC experiments were recorded with a Nucleosil-5 C18 column $(4.5 \mathrm{~mm}$ $\times 250 \mathrm{~mm}$ ), and solvents were of HPLC grade; the mobile phase was 90-100\% (v/v) $\mathrm{MeOH} / \mathrm{H}_{2} \mathrm{O}$. Compounds 5 and 6 were prepared according to literature procedures. ${ }^{11}$

Photocyclization of $3 a$ to $1 \mathrm{a}$. A mixture of compound $3 \mathrm{a}(0.10 \mathrm{~g}$, $0.215 \mathrm{mmol})$ and a catalytic amount of iodine $(0.547 \mathrm{mg}, 0.0022$ $\mathrm{mmol})$ in THF $(250 \mathrm{~mL})$ was stirred at room temperature and irradiated in a Rayonet photoreactor at $300 \mathrm{~nm}$ for $8 \mathrm{~h}$. The solvent was removed under reduced pressure. The residue was dissolved in $\mathrm{CH}_{2} \mathrm{Cl}_{2}$, washed with a $10 \%$ aqueous solution of $\mathrm{Na}_{2} \mathrm{~S}_{2} \mathrm{O}_{3}$ followed by a saturated aqueous solution of $\mathrm{Na}_{2} \mathrm{CO}_{3}$, and dried over anhydrous $\mathrm{MgSO}_{4}$, and then the solvent was evaporated under reduced pressure. The resulting residue was purified by flash column chromatography (hexane, $R_{\mathrm{f}}=0.5$ ) to afford a mixture of $3 \mathbf{a}$ and $1 \mathrm{a}$ in which 1a was obtained in $58 \%$ yield based on ${ }^{1} \mathrm{H}$ NMR peak ratios. Single crystals of 1a were obtained from crystallization of the mixture of $\mathbf{3 a}$ and $\mathbf{1 a}$ using a mixed solvent of dichloromethane and ethanol $(2: 8 \mathrm{v} / \mathrm{v}) .{ }^{1} \mathrm{H}$ NMR $\left(300 \mathrm{MHz}, \mathrm{CDCl}_{3}\right): \delta_{\mathrm{H}} 8.49(\mathrm{~d}, J=8.1 \mathrm{~Hz}, 2 \mathrm{H}), 7.38(\mathrm{~m}, 3.0 \mathrm{~Hz}, 4 \mathrm{H})$, $7.34-7.19(\mathrm{~m}, 8 \mathrm{H}), 7.05(\mathrm{~d}, J=8.1 \mathrm{~Hz}, 2 \mathrm{H}), 7.00-6.88(\mathrm{~m}, 2 \mathrm{H}), 2.79$ $(\mathrm{s}, 4 \mathrm{H}), 2.04(\mathrm{~d}, J=9.3 \mathrm{~Hz}, 4 \mathrm{H}), 1.72(\mathrm{~d}, J=9.7 \mathrm{~Hz}, 4 \mathrm{H}) .{ }^{13} \mathrm{C} \mathrm{NMR}$ $\left(75.4 \mathrm{MHz}, \mathrm{CDCl}_{3}\right): \delta_{\mathrm{C}} 147.3(\mathrm{Cq}), 138.5(\mathrm{Cq}), 130.3(\mathrm{Cq}), 130.3$ (Cq), $128.8(\mathrm{CH}), 128.0(\mathrm{CH}), 126.0(\mathrm{CH}), 125.9(\mathrm{CH}), 124.5$ $(\mathrm{CH}), 124.0(\mathrm{CH}), 122.9(\mathrm{CH}), 56.7(\mathrm{Cq}), 48.2(\mathrm{CH}), 29.7\left(\mathrm{CH}_{2}\right)$, $25.4\left(\mathrm{CH}_{2}\right)$. EI-MS: $m / z 463\left([\mathrm{M}+\mathrm{H}]^{+}\right)$. HRMS (EI): $m / z$ calcd for $\mathrm{C}_{36} \mathrm{H}_{30} 462.2348$, found 462.2351 .

X-ray Crystal Data for (1a) $)_{3} \cdot \mathrm{CH}_{2} \mathrm{Cl}_{2} \cdot \mathrm{C}_{109} \mathrm{H}_{92} \mathrm{Cl}_{2}, M=1472.73$, monoclinic, $a=16.037(3) \AA, b=11.554(2) \AA, c=21.481(4) \AA, \alpha=$ $90^{\circ}, \beta=109.402(4)^{\circ}, \gamma=90^{\circ}, V=3754.0(13) \AA^{3}$, space group $P \overline{1}, Z=$ 2 , calculated density $1.303 \mathrm{Mg} / \mathrm{m}^{-3}$, crystal dimensions: $0.52 \mathrm{~mm} \times$ $0.50 \mathrm{~mm} \times 0.08 \mathrm{~mm}, T=200(2) \mathrm{K}, \lambda(\mathrm{Mo} \mathrm{K} \alpha)=0.71073 \AA, \mu=0.142$ $\mathrm{mm}^{-1}, 24974$ reflections collected, 6543 independent reflections $\left(R_{\text {int }}\right.$ $=0.0981), 501$ parameters refined on $F^{2}, R_{1}=0.0673, w R_{2}\left(F^{2}\right)=$ 0.1621 (all data), goodness of fit on $F^{2}=1.018, \Delta \rho_{\max }=0.342 \mathrm{e} \AA^{-3}$. CCDC 963498 contains the supplementary crystallographic data for this paper. These data can be obtained free of charge from the Cambridge Crystallographic Data Centre via www.ccdc.cam.ac.uk/ data_request/cif.

Synthesis of $\mathbf{2 b}$. To a solution of $\mathbf{6}(0.49 \mathrm{~g}, 1.99 \mathrm{mmol})$ and $\mathrm{KOH}$ $(0.06 \mathrm{~g}, 1.07 \mathrm{mmol})$ in EtOH $(15 \mathrm{~mL})$ was added 1,3-diphenylacetone $(0.42 \mathrm{~g}, 1.99 \mathrm{mmol})$, and the mixture was refluxed for $30 \mathrm{~min}$ and then cooled to room temperature. The solvent was removed under reduced pressure, and the residue was partitioned between $\mathrm{H}_{2} \mathrm{O}(30 \mathrm{~mL})$ and $\mathrm{CH}_{2} \mathrm{Cl}_{2}(50 \times 3 \mathrm{~mL})$. The combined organic layers were dried over anhydrous $\mathrm{MgSO}_{4}$ and evaporated. The residue was recrystallized from EtOH to afford the product $\mathbf{2 b}$ as a dark-red solid in $35 \%$ yield. $\mathrm{Mp}$ 160-161 ${ }^{\circ} \mathrm{C} .{ }^{1} \mathrm{H}$ NMR $\left(\mathrm{CDCl}_{3}, 300 \mathrm{MHz}\right): \delta_{\mathrm{H}} 7.35-7.29(\mathrm{~m}, 5 \mathrm{H})$, 6.98-6.86 (m, 4H). ${ }^{13} \mathrm{C}$ NMR $\left(\mathrm{CDCl}_{3}, 75.4 \mathrm{MHz}\right): \delta_{\mathrm{C}} 199.4(\mathrm{Cq})$, $159.3(\mathrm{~d}, J=248 \mathrm{~Hz}, \mathrm{Cq}), 149.3(\mathrm{Cq}), 130.6(\mathrm{~d}, J=8.4 \mathrm{~Hz}, \mathrm{CH})$, $130.4(\mathrm{Cq}), 130.2(\mathrm{CH}), 129.4(\mathrm{CH}), 128.1(\mathrm{CH}), 127.8(\mathrm{CH}), 126.6$ $(\mathrm{CH}), 123.9(\mathrm{CH}), 121.4(\mathrm{~d}, J=17 \mathrm{~Hz}, \mathrm{Cq}), 115.7(\mathrm{~d}, J=22 \mathrm{~Hz}$, CH). EI-MS: $m / z 420.1\left(\mathrm{M}^{+}\right)$. HRMS (EI): $m / z$ calcd for $\mathrm{C}_{29} \mathrm{H}_{18} \mathrm{~F}_{2} \mathrm{O}$ 420.1326 , found 420.1333 .

Synthesis of 3a.9 Compound $2 \mathrm{a}(2.50 \mathrm{~g}, 6.51 \mathrm{mmol})$ in 1,5cyclooctadiene $(10 \mathrm{~mL})$ was heated at reflux for 4 days. After cooling to room temperature, the suspension was filtered to afford the product $3 \mathrm{a}$ as a white solid $(2.14 \mathrm{~g}, 71 \%) . \mathrm{Mp} 305-306{ }^{\circ} \mathrm{C} .{ }^{1} \mathrm{H}$ NMR (300 $\left.\mathrm{MHz}, \mathrm{CDCl}_{3}\right): \delta_{\mathrm{H}} 7.23(\mathrm{~d}, J=7.4 \mathrm{~Hz}, 4 \mathrm{H}), 7.00(\mathrm{t}, J=7.5 \mathrm{~Hz}, 4 \mathrm{H})$, $6.89(\mathrm{t}, J=7.2 \mathrm{~Hz}, 2 \mathrm{H}), 6.72-6.56(\mathrm{~m}, 6 \mathrm{H}), 6.51(\mathrm{dd}, J=7.6,1.7 \mathrm{~Hz}$ $4 \mathrm{H}), 2.88(\mathrm{~s}, 4 \mathrm{H}), 1.95(\mathrm{~d}, J=9.1 \mathrm{~Hz}, 4 \mathrm{H}), 1.54(\mathrm{~s}, 4 \mathrm{H}) .{ }^{13} \mathrm{C} \mathrm{NMR}$ $\left(75.4 \mathrm{MHz}, \mathrm{CDCl}_{3}\right): \delta_{\mathrm{C}} 144.8(\mathrm{Cq}), 142.2(\mathrm{Cq}), 141.4(\mathrm{Cq}), 130.6$ $(\mathrm{CH}), 128.4(\mathrm{CH}), 127.0(\mathrm{CH}), 126.0(\mathrm{CH}), 124.9(\mathrm{CH}), 124.2$ $(\mathrm{CH}), 56.6(\mathrm{Cq}), 45.8(\mathrm{CH}), 25.01\left(\mathrm{CH}_{2}\right)$. EI-MS: $m / z 464.4\left(\mathrm{M}^{+}\right)$. HRMS (EI): $m / z$ calcd for $\mathrm{C}_{36} \mathrm{H}_{32} 464.2504$, found 464.2496 .

Synthesis of $\mathbf{3 b}$. A solution of compound $\mathbf{2 b}(0.10 \mathrm{~g}, 0.238 \mathrm{mmol})$ in 1,5-cyclooctadiene $(0.37 \mathrm{~mL})$ was heated at reflux for $24 \mathrm{~h}$. After cooling to room temperature, the suspension was filtered to afford the product $3 \mathrm{~b}$ as a white solid $(8.30 \mathrm{mg}, 68 \%)$. Mp $275-276{ }^{\circ} \mathrm{C} .{ }^{1} \mathrm{H}$ $\operatorname{NMR}\left(300 \mathrm{MHz}, \mathrm{CDCl}_{3}\right): \delta_{\mathrm{H}} 7.44(\mathrm{~d}, J=9.0 \mathrm{~Hz}, 2 \mathrm{H}), 7.20(\mathrm{~d}, J=9.0$ $\mathrm{Hz}, 2 \mathrm{H}), 7.08-6.88(\mathrm{~m}, 6 \mathrm{H}), 6.67-6.58(\mathrm{~m}, 4 \mathrm{H}), 6.50(\mathrm{t}, J=7.2 \mathrm{~Hz}$, $2 \mathrm{H}), 6.40(\mathrm{t}, J=8.9 \mathrm{~Hz}, 2 \mathrm{H}), 6.52-6.47(\mathrm{~m}, 1 \mathrm{H}), 3.0(\mathrm{~d}, J=12.1 \mathrm{~Hz}$, $2 \mathrm{H}), 2.86(\mathrm{~m}, 2 \mathrm{H}), 2.04-1.88(\mathrm{~m}, 4 \mathrm{H}), 1.68-1.45(\mathrm{~m}, 4 \mathrm{H}) .{ }^{13} \mathrm{C}$ $\operatorname{NMR}\left(75.4 \mathrm{MHz}, \mathrm{CDCl}_{3}\right): \delta_{\mathrm{C}} 190.2(\mathrm{Cq}), 162.9(\mathrm{~d}, J=254 \mathrm{~Hz}, \mathrm{Cq})$, 136.7 (dd, $\left.J_{1}=6 \mathrm{~Hz}, J_{2}=4 \mathrm{~Hz}, \mathrm{CH}\right), 130.7(\mathrm{CH}), 124.9(\mathrm{CH}), 121.2$ $\left(\mathrm{dd}, J_{1}=10 \mathrm{~Hz}, J_{2}=3 \mathrm{~Hz}, \mathrm{Cq}\right), 116.4(\mathrm{~d}, J=22 \mathrm{~Hz}, \mathrm{CH})$. EI-MS: $m / z$ $500.2\left(\mathrm{M}^{+}\right)$. HRMS (EI): $\mathrm{m} / z$ calcd for $\mathrm{C}_{36} \mathrm{H}_{30} \mathrm{~F}_{2}$ 500.2316, found 500.2305

Photocyclization of $\mathbf{3 b}$ to $1 \mathrm{a}-\mathrm{c}$. A mixture of compound $\mathbf{3 b}$ $(0.1 \mathrm{~g}, 0.199 \mathrm{mmol})$ and a catalytic amount of iodine $(5.0 \mathrm{mg}, 0.0197$ $\mathrm{mmol})$ in THF $(100 \mathrm{~mL})$ was stirred at room temperature and irradiated at $250 \mathrm{~nm}$ in a Rayonet photoreactor for $8 \mathrm{~h}$. The solvent was removed under reduced pressure. The residue was dissolved in $\mathrm{CH}_{2} \mathrm{Cl}_{2}$, washed with a $10 \%$ aqueous solution of $\mathrm{Na}_{2} \mathrm{~S}_{2} \mathrm{O}_{3}$ followed by a saturated aqueous solution of $\mathrm{Na}_{2} \mathrm{CO}_{3}$, and dried over anhydrous $\mathrm{MgSO}_{4}$, and then the solvent was evaporated under reduced pressure. The resulting residue was purified by column chromatography (hexane, $R_{\mathrm{f}}=0.5$ ) and recrystallization. However, the reaction mixture analyzed by HPLC still showed three major peaks at $r_{\mathrm{t}}=23.9,24.8$, 
and 25.9 min with an area ratio of 8:85:5. The mixture of compounds $1 \mathrm{a}-\mathrm{c}$ was also confirmed by EI-MS and HRMS. For 1a: $m / z 463$ ([M $+\mathrm{H}^{+}$); HRMS (EI) calcd for $\mathrm{C}_{36} \mathrm{H}_{30} 462.2348$, found 462.2354. For 1c: $m / z 481\left([\mathrm{M}+\mathrm{H}]^{+}\right)$; HRMS (EI) calcd for $\mathrm{C}_{36} \mathrm{H}_{29} \mathrm{~F}$ 480.2253, found 480.2250. For $\mathbf{1 b}: m / z 498\left(\mathrm{M}^{+}\right)$; HRMS (EI) calcd for $\mathrm{C}_{36} \mathrm{H}_{29} \mathrm{~F}_{2} 498.2159$, found 498.2163 . The $1 \mathrm{~b}: 1 \mathrm{c}: 1$ a peak-area ratio was determined to be $8: 85: 5$ by HPLC analysis.

\section{ASSOCIATED CONTENT}

\section{S Supporting Information}

Crystallographic data for 1a (CIF); ${ }^{1} \mathrm{H}$ and ${ }^{13} \mathrm{C}$ NMR spectra and MS data for compounds $1 \mathbf{a}-\mathbf{c}, \mathbf{2 b}, \mathbf{3 a}, 3 \mathbf{b}, \mathbf{5}$, and $\mathbf{6}$; and $\mathrm{DMol} 3$ calculation data for compounds $1 \mathrm{a}-\mathbf{c}$. This material is available free of charge via the Internet at http://pubs.acs.org.

\section{AUTHOR INFORMATION}

\section{Corresponding Authors}

*E-mail: tselokho@yahoo.com.

*E-mail: wschung@nctu.edu.tw.

\section{Notes}

The authors declare no competing financial interest.

\section{ACKNOWLEDGMENTS}

We thank the National Science Council (NSC) and the MOE ATU Program of the Ministry of Education, Taiwan, Republic of China, for financial support.

\section{REFERENCES}

(1) (a) Salonen, L. M.; Ellermann, M.; Diederich, F. Angew. Chem.. Int. Ed. 2011, 50, 4808-4842. (b) Jose, D.; Datta, A. I. Phvs. Chem. Lett. 2010, 1, 1363-1366. (c) Raghavender, U. S.; Aravinda, S.; Shamala, N.; Kantharaju; Rai, R.; Balaram, P. I. Am. Chem. Soc. 2009, 131, 15130-15132. (d) Zhao, R; Matsumoto, S.; Akazome, M.; Ogura, K. Tetrahedron 2002, 58, 10233-10241. (e) Brandl, M.; Weiss, M. S.; Jabs, A.; Sühnel, J.; Hilgenfeld, R. I. Mol. Biol. 2001, 307, 357377. (f) Takahashi, H.; Tsuboyama, S.; Umezawa, Y.; Honda, K.; Nishio, M. Tetrahedron 2000, 56, 6185-6191.

(2) (a) Zhao, C.; Parrish, R. M.; Smith, M. D.; Pellechia, P. J.; Sherrill, C. D.; Shimizu, K. D. I. Am. Chem. Soc. 2012, 134, 1430614309. (b) Nijamudheen, A.; Jose, D.; Shine, A.; Datta, A. I. Phys. Chem. Lett. 2012, 3, 1493-1496. (c) Carroll, W. R.; Zhao, C.; Smith, M. D.; Pellechia, P. J.; Shimizu, K. D. Org. Lett. 2011, 13, 4320-4323.

(3) (a) Tsuzuki, S. Annu. Rep. Prog. Chem., Sect. C: Phvs. Chem. 2012, 108, 69-95. (b) Nishio, M.; Umezawa, Y.; Honda, K.; Tsuboyama, S.; Suezawa, H. CrustEngComm 2009, 11, 1757-1788.

(4) (a) Sun, H.; Tottempudi, U. K.; Mottishaw, J. D.; Basa, P. N.; Putta, A.; Sykes, A. G. Cryst. Growth Des. 2012, 12, 5655-5662. (b) Chopra, D.; Guru Row, T. N. CrystEnoComm 2011, 13, 21752186. (c) Hunter, L. Beilstein J. Org. Chem. 2010, 6, 1-14. (d) Bissantz, G.; Kuhn, B.; Stahl, M. I. Med. Chem. 2010, 53, 5061-5084.

(5) (a) Alkorta, I.; Rozas, I.; Elguero, J. I. Fluorine Chem. 2000, 100, 233-238. (b) Kawahara, S.-I.; Tsuzuki, S.; Uchimaru, T. I. Phvs. Chem. A 2004, 108, 6744-6749.

(6) Nowak, I. L. Fluorine Chem. 1999, 99, 59-66.

(7) Scerba, M. T.; Bloom, S.; Haselton, N.; Siegler, M.; Jaffe, J.; Lectka, T. I. Org. Chem. 2012, 77, 1605-1609.

(8) (a) Ho, T.-L. Tandem Reactions in Organic Synthesis; Wiley: New York, 1992. (b) Winkler, J. D. Chem. Rev. 1996, 96, 167-176.

(9) Akhtar, I. A.; Fray, G. I.; Yarrow, J. M. J. Chem. Soc. C 1968, 812815 .

(10) (a) Mallory, F. B.; Mallory, C. W. Org. React. 1984, 30, 1-456. (b) Mallory, F. B.; Wood, C. S.; Gordon, J. T. I. Am. Chem. Soc. 1962, 84, 4361-4362. (c) Mallory, F. B.; Gordon, J. T.; Wood, C. S. I.Am. Chem. Soc. 1963, 85, 828-829. (d) Mallory, F. B.; Wood, C. S.; Gordon, J. T. I. Am. Chem. Soc. 1964, 86, 3094-3102. (e) Wood, C. S.; Mallory, F. B. I. Org. Chem. 1964, 29, 3373-3377. (f) Mallory, F.
B.; Mallory, C. W. J. Am. Chem. Soc. 1972, 94, 6041-6048. (g) Lewis, F. D.; Kurth, T. L.; Kalgutkar, R. S. Chem. Commun. 2001, 1372-1373.

(11) Romanov-Michailidis, F.; Besnard, C.; Alexakis, A. Org. Lett. 2012, 14, 4906-4909.

(12) Stadlbauer, S.; Ohmori, K.; Hattori, F.; Suzuki, K. Chem. Commun. 2012, 48, 8425-8427.

(13) (a) Dewar, M. J. S.; Kelemen, J. I. Chem. Phvs. 1968, 49, 499508. (b) Byrne, P. A.; Rajendran, K. V.; Muldoon, J.; Gilheany, D. G. Org. Biomol. Chem. 2012, 10, 3531-3537. (c) Luthe, G.; Ariese, F.; Brinkman, U. A. Th. Chromatographia 2004, 59, 37-41.

(14) This unexpected deshielding was explained as due to the direct overlap of the van der Waals radii of the adjacent substituents and fluorine, causing the restricted motion of electrons on the fluorine and thus making the fluorine nucleus respond to the magnetic field as if the electron density were lowered. See: (a) Dolbier, W. R. Guide to Fluorine NMR for Oroanic Chemists: Wiley: New York, 2009. (b) Gribble, G. W.; Keavy, D. J.; Olson, E. R.; Rae, I. D.; Staffa, A.; Herr, T. E.; Ferraro, M. B.; Contreras, R. H. Magn. Reson. Chem. 1991, 29, 422-432. Also see: (c) Rae, I. D.; Staffa, A.; Diz, A. C.; Giribet, C. G.; Ruiz de Azúa, M. C.; Contreras, R. H. Aust. I. Chem. 1987, 40, 1923-1940. (d) Dolbier, W. R.; Gray, T. A.; Keaffaber, J. J.; Celewicz, L.; Koroniak, H. I. Am. Chem. Soc. 1990, 112, 363-367. (e) Landelle, G.; Turcotte-Savard, M.-O.; Angers, L.; Paquin, J.-F. Org. Lett. 2011, 13, 1568-1571. (f) Uno, H.; Sakamoto, K.; Semba, F.; Suzuki, H. Bull. Chem. Soc. Ipn. 1992, 65, 210-217. (g) Ernst, L.; Ibrom, K. Magn. Reson. Chem. 1997, 35, 868-876. (h) Furuya, T.; Kaiser, H. M.; Ritter, T. Angew. Chem. 2008, 120, 6082-6085. (i) Fifolt, M. J.; Sojka, S. A.; Wolfe, R. A.; Hojnicki, D. S. I. Org. Chem. 1989, 54, 3019-3023. (j) Taft, R. W.; Price, E.; Fox, I. R.; Lewis, I. C.; Anderson, K. K.; Davis, G. T. I. Am. Chem. Soc. 1963, 85, 3146-3156. (k) Taft, R. W.; Price, E.; Fox, I. R.; Lewis, I. C.; Anderson, K. K.; Davis, G. T. I. Am. Chem. Soc. 1963, 85, 709-724.

(15) (a) Delley, B. I. Chem. Phys. 1990, 92, 508-517. (b) Delley, B. I. Chem. Phys. 2000, 113, 7756-7764. (c) Benedek, N. A.; Snook, I. K.; Latham, K.; Yarovsky, I. J. Chem. Phys. 2005, 122, No. 144102.

(16) Mooibroek, T. J.; Gamez, P. CrystEngComm 2012, 14, 84628467.

(17) Saielli, G.; Bini, R.; Bagno, A. Theor. Chem. Acc. 2012, 131, 1140. 